\title{
SUMO2 modification of Aurora B and its impact on follicular development and atresia in the mouse ovary
}

\author{
JING CAO, XIAO-MING LIU, LI-LIN HUANG, LI WANG, XIAO-FEI JIAO and LI-JUN HUO
}

\begin{abstract}
Key Laboratory of Agricultural Animal Genetics, Breeding and Reproduction, Education Ministry of China, College of Animal Science and Technology, Huazhong Agricultural University, Wuhan, Hubei 430070, P.R. China
\end{abstract}

Received October 9, 2016; Accepted December 29, 2017

DOI: $10.3892 /$ ijmm.2018.3541

\begin{abstract}
In the mammalian ovary, $>99 \%$ follicles fail to ovulate due to apoptosis in granulosa cells. Aurora B, a core subunit enzyme of the chromosomal passenger complex, exerts a crucial role in microtubule-kinetochore attachment, and has been reported to be modified by small ubiquitin-related modifier (SUMO) proteins. However, the details of how Aurora B and its SUMOylation impact on follicular development have yet to be fully elucidated. The aim of the present study was to explore the roles, and possible molecular mechanism, of Aurora B and its SUMOylation in the granulosa cells of the mouse follicle. It was revealed that the protein level of Aurora B increased with follicular development and the growth of the granulosa cells. Aurora B impacted follicular development and atresia through mediating the p38 mitogen-activated protein kinase and FasL/Fas pathways, and caused the downregulation of cyclin-dependent kinase 4, proliferating cell nuclear antigen, Bcl-2, and upregulation of caspases-3 and -8 to modulate the viability of the granulosa cells. In addition, Aurora B undergoes modification by SUMO2, but not by SUMO1, in vivo and in vitro, and Lys-207 is a major modification site. SUMOylation modulates follicular development through an increase in Aurora B localization in the nucleus, and by stabilizing the protein level of Aurora B and keeping the viability of the granulosa cells. Taken together, Aurora B and its SUMOylation are important for follicular development and atresia in the ovaries of mice.
\end{abstract}

Correspondence to: Dr Li-Jun Huo, Key Laboratory of Agricultural Animal Genetics, Breeding and Reproduction, Education Ministry of China, College of Animal Science and Technology, Huazhong Agricultural University, 1 Shizishan Street, Hongshan, Wuhan, Hubei 430070, P.R. China

E-mail: lijunhuo@yahoo.com

Key words: small ubiquitin-related modifier, Aurora B, apoptosis, p38 mitogen-activated protein kinase

\section{Introduction}

A mammalian ovary consists of a large number of follicles at the fetal stage. However, $>99 \%$ of follicles fail to ovulate due to follicular atresia, which is the spontaneous degeneration of a follicle (1). Although follicular atresia may occur at any stage of growth and development (2), it usually occurs during the early antral stages of follicular development. As a result, apoptosis is originally induced in the region of the granulosa cells, as opposed to the cumulus cells, oocytes, or inner or extra theca cells, and subsequently the majority of the granulosa cells, theca cells and cumulus cells undergo apoptosis. This firmly suggests that follicular development and atresia predominantly depend on apoptosis of the granulosa cells. In addition, previous studies have demonstrated that numerous factors, including cell death ligands and receptors, growth factors, pro- and anti-apoptotic factors, apoptotic genes and cytokines, may modulate apoptosis of the granulosa cells (2).

Aurora B (also termed serine/threonine-protein kinase 12) is a key regulator in mitosis. It forms the enzymatic core of the chromosomal passenger complex (CPC) (3), which also contains three non-enzymatic components: Survivin, inner centromere protein (INCENP) and borealin (4). CPC is a crucial upstream regulator of centromere-kinetochore function. Aurora B exerts an important role in chromosomal cohesion and arrangement, chromosomal separation, the spindle assembly checkpoint, and cytokinesis (5). During mitosis, the localization of Aurora B changes during cell cycle division: For example, Aurora B is localized on the inner centromeres during metaphase to regulate chromosomal cohesion and spindle-kinetochore attachment (6); subsequently, it is localized on the spindle midzone and equatorial cortex, and then it accumulates in the midbody to accomplish cell division $(6,7)$. Aurora B may be activated by autophosphorylation of the T-loop (activation loop) after it binds to the IN-box region of INCENP $(8,9)$. Post-translational modifications, including ubiquitination and SUMOylation, are necessary for the proper activity and control of the dynamic behavior of the CPC.

SUMOylation is a post-translational modification by the covalent conjugation of small ubiquitin-related modifiers (SUMOs), which are found in all eukaryotes (10-12). There are at least three forms of SUMOs that have been identified in humans: SUMO1, 2 and 3. SUMO2 and 3 have a high 
degree of similarity (97\%), whereas SUMO1 shares $43 \%$ of its identity with SUMO2/3 (13). Similarly to ubiquitination, SUMOylation features a conserved sequence that covalently conjugates to lysine residues within the target protein using the sequential action of SUMO-specific E1 (activation), E2 (conjugation) and E3 (ligation) enzymes (14). This process may result in a modulation of the subcellular localization of its targets (15), alter protein stability (16), and antagonize other types of post-translational modifications $(17,18)$ in at least two ways: An allosteric effect that induces substrate conformational change, or an effect that involves the creation/inhibition of a binding interface (6). SUMOylation is also a reversible process that is catalyzed by the SUMO-specific proteases of the sentrin-specific protease (SENP) family (19).

The majority of studies have focused on the role of Aurora B in cancer therapy; however, the role of Aurora B and its SUMOylation in follicular development and atresia has yet to be elucidated. A recent study has verified that, in humans, Aurora B is modified by PIAS3 [protein inhibitor of activated signal transducer and activator of transcription (STAT)]-mediated SUMO2 conjugation at Lys-202, and that SUMO2 conjugation facilitates the autophosphorylation of Aurora B, but does not directly affect its kinase activity during mitosis (6). Furthermore, Lys-207 of Aurora B may be conjugated to SUMOs in 293 cells, and this modification requires Aurora B to bind to its activator, INCENP. The defective SUMOylation of Aurora B has resulted in abnormal chromosome segregation, reduced cell viability, and altered cytokinesis and chromosomal dynamics of the CPC (20).

However, upon sequencing cDNA obtained from the granulosa cells of Kunming female white mice, the individual base (134 bp) of Mus musculus Aurora B has been identified and verified that is different, as reported by The National Center for Biotechnology Information (NCBI; cDNA clone MGC:5803 IMAGE:3501444). In addition, recent proteomics studies have shown that a considerable proportion of SUMOylated proteins do not contain the consensus sites (21-23), and that not all consensus sequences are SUMOylated, as this process often occurs outside of the consensus sequence (24). Therefore, the aim of the present study was to determine how Aurora B and its SUMOylation may influence follicular development and atresia in primary cultured granulosa cells in mice.

The findings of the present study have provided evidence that, in mice, Aurora B serves a crucial role in follicular development through mediating the viability of granulosa cells, with possibly other molecular mechanisms being in operation. Furthermore, this study has explored whether Aurora B may be SUMO-modified at Lys-207 in vivo and in vitro. How SUMOylation impacts on follicular development and atresia, as mediated by granulosa cells, was also examined.

\section{Materials and methods}

Experimental animals and ethics. Female Kunming mice were purchased from the Center of Laboratory Animals (Wuhan, China). All animal treatment procedures were approved by the Ethics Committee of the Hubei Research Center of Experimental Animals (ref. no. ETH-201509). The mice were provided with food and water, and housed under controlled conditions of temperature $\left(20-24^{\circ} \mathrm{C}\right)$ and lighting (12-h light/12-h darkness).
Immunohistochemistry (IHC). The ovaries from mice aged 7, 14 or 21 days, or from 21-day mice that had been injected with 10 IU pregnant mare serum gonadotropin (PMSG; Ningbo Sansheng Pharmaceutical Co., Ltd., Ningbo, China) for $48 \mathrm{~h}$, or from 21-day mice that had been injected with 10 IU human chorionic gonadotropin (hCG; Ningbo Sansheng Pharmaceutical Co., Ltd.) for $7 \mathrm{~h}$ after treatment with PMSG for $48 \mathrm{~h}$, were collected. The ovaries were fixed in $4 \%$ paraformaldehyde (PFA; Santa Cruz Biotechnology, Inc., Santa Cruz, CA, USA) overnight at $4^{\circ} \mathrm{C}$, passed through an ethanol gradient series for dehydration, and embedded in paraffin wax. The ovaries were then cut into 4-5 $\mu \mathrm{m}$ sections, which were placed on slides. The slides were dewaxed in xylene and rehydrated in gradient ethanol. Heat-mediated antigen retrieval of tissue sections was performed before the sections were allowed to cool (25). Endogenous peroxidases were blocked using $3 \%$ hydrogen peroxide for 15 to $20 \mathrm{~min}$, and non-specific antibody binding was blocked using $5 \%$ bovine serum albumin (BSA; Sigma-Aldrich, St. Louis, MO, USA) for $1 \mathrm{~h}$. The tissue sections were incubated with polyclonal rabbit anti-Aurora B antibody (1:200 dilution; sc-25426; Santa Cruz Biotechnology, Inc.) overnight at $4^{\circ} \mathrm{C}$, and then incubated with a secondary antibody and streptavidin-biotin complex (SA1022; Wuhan Boster Biological Technology, Ltd., Wuhan, China) for $20 \mathrm{~min}$ at $37^{\circ} \mathrm{C}$. The signals were visualized using 3,3'-diaminobenzidine (DAB) for $1 \mathrm{~min}$ and hematoxylin for $2 \mathrm{~min}$. Slides were subsequently dehydrated using graded ethanol, cleared in xylene, mounted, and images were captured.

Immunocytochemistry (ICC). For immunofluorescence, granulosa cells from antral follicles were obtained from the ovaries of 21-day-old female Kunming mice injected with 10 IU PMSG for $48 \mathrm{~h}$. To obtain purified granulosa cells, it is necessary that the ovaries are not minced too extensively; the tissues were then suspended in Dulbecco's modified Eagle's medium/Nutrient F12 (DMEM/F12; Hyclone, Logan, UT, USA) or phosphate-buffered saline (PBS) three times; the suspension time was reduced from $1 \mathrm{~min}$ to $30 \mathrm{sec}$. The supernatant containing the granulosa cells was centrifuged at $252 \mathrm{x}$ g for $5 \mathrm{~min}$ at room temperature, and cultured in DMEM/ F12 medium supplemented with $10 \%$ fetal bovine serum (FBS; Gibco; Thermo Fisher Scientific, Inc., Waltham, MA, USA) at $37^{\circ} \mathrm{C}$ in a humidified atmosphere containing $5 \% \mathrm{CO}_{2}$. After $12 \mathrm{~h}$, granulosa cells were washed with DMEM/F12 to remove impurities and tissues, and cultured in fresh medium continuously. Cells were fixed in 4\% PFA and permeabilized with $0.5 \%$ Triton X-100 (Santa Cruz Biotechnology, Inc.). The cells were subsequently blocked with 5\% BSA for $30 \mathrm{~min}$ at $37^{\circ} \mathrm{C}$ and incubated with primary antibodies overnight at $4^{\circ} \mathrm{C}$, a polyclonal rabbit anti-Aurora $\mathrm{B}$ antibody (1:100 dilution; sc-25426; Santa Cruz Biotechnology, Inc.), a monoclonal mouse anti-HA antibody (1:500 dilution; M180-3; Medical and Biological Laboratories, Co., Ltd., Nagoya, Japan), and a polyclonal rabbit anti-Flag antibody (1:200 dilution; 20543-1-AP; Proteintech, Chicago, IL, USA). The next day, the cells were incubated with fluorescein isothiocyanate (FITC)/CY3 conjugated to a secondary antibody (1:100 dilution; Wuhan Boster Biological Technology, Ltd.) for $2 \mathrm{~h}$ at room temperature in the dark. The nuclei were stained with $10 \mu \mathrm{l} / \mathrm{ml}$ propidium iodide (PI; Santa Cruz Biotechnology, 
Table I. Sequences of primer pairs for PCR.

\begin{tabular}{lll}
\hline Gene & & Primer sequences $\left(5^{\prime} \rightarrow 3^{\prime}\right)$ \\
\hline Aurora $B$ & Forward & CAAGCTTTGTTTCCCTCTCTGTCCA \\
Rurora $B^{K 207 R}$ & Feverse & GGAATTCAACCAAGGAGCAGGCTA \\
& Forward 1 & CAAGCTTTGTTTCCCTCTCTGTCCA \\
& Reverse 1 & AGGTTCTCCGGCTTTATGTCT \\
& Forward 2 & TAATTCACAGAGACATAAAGCCGG \\
Reverse 2 & GGAATTCAACCAAGGAGCAGGCTA \\
& Forward & GCTCCTGGTGCTGCTTGTG \\
& Reverse & CCCTTTTTAGTAGACACCTCCAGT
\end{tabular}

PCR, polymerase chain reaction; SUMO2, small ubiquitin-related modifier.

Inc.) for $5 \mathrm{~min}$ in the dark. Images were then captured using a microscope (TE2000-U; Nikon, Tokyo, Japan).

Plasmid construction. The Aurora B- and SUMO2-coding sequences of Mus musculus were obtained from the National Center for Biotechnology Information (Bethesda, MD, USA) (Aurora B, NM_011496.2; SUMO2, NM_133354), and were amplified using the polymerase chain reaction (PCR) and primer pair sequences (Table I). To generate the Aurora B lysine 207-to-arginine (K207R) mutant, two primer pairs were used for PCR: The Aurora B cDNA sequence was used as the template using primer pair 1 (forward 1 and reverse 1) and primer pair 2 (forward 2 and reverse 2), respectively, for generating two fragments including the mutant base, and then the two fragments (1:1) were taken as the template again, this time using the primer pair, forward 1 and reverse 2 , for the second reaction. The genes were then subcloned into pCMV-N-HA or Flag vector to generate the plasmids, named as HA-Aurora B, HA-Aurora B ${ }^{\mathrm{K} 207 \mathrm{R}}$ and HA-SUMO2, and Flag-Aurora B, Flag-Aurora B ${ }^{\text {K207R }}$ and Flag-SUMO2. The results were confirmed by sequencing.

Cell culture, inhibitor treatment and transfection. Ovaries from 21-day mice were injected with PMSG for $48 \mathrm{~h}$. The ovaries were subsequently minced using a scalpel, and suspended in DMEM/F12 or PBS three times; the time of the suspensions was reduced from $1 \mathrm{~min}$ to $30 \mathrm{sec}$. The supernatant containing the granulosa cells was cultured in DMEM/F12 supplemented with $10 \% \mathrm{FBS}$ at $37^{\circ} \mathrm{C}$ in a humidified atmosphere containing 5\% $\mathrm{CO}_{2}$. ZM447439 (Axon Medchem LLC, Reston, VA, USA), an inhibitor of Aurora B, was dissolved in DMSO at concentrations of 10,50 , and $100 \mathrm{mM}$, and stored at $-20^{\circ} \mathrm{C}$. Appropriate concentrations were added to the culture medium for $48 \mathrm{~h}$ after the cells were starved for $6 \mathrm{~h}$; the final concentration of DMSO never exceeded $1 \mu \mathrm{l} / \mathrm{ml}$. HA-Aurora B, HA-Aurora $\mathrm{B}^{\mathrm{K} 207 \mathrm{R}}$, Flag-SUMO2 and HA or Flag (as control) were transfected using Lipofectamine ${ }^{\circledR}$ LTX and Plus ${ }^{\mathrm{TM}}$ reagent (Invitrogen Life Technologies; Thermo Fischer Scientific, Inc.) according to the manufacturer's protocol. Lipofectamine ${ }^{\circledR}$ LTX and plasmids were diluted into Opti-MEM (Gibco; Thermo Fischer Scientific, Inc.) for $5 \mathrm{~min}$, and then mixed in a ratio of 2:1 for $30 \mathrm{~min}$. After $48 \mathrm{~h}$, the granulosa cells were collected for protein extraction or subsequent assay.
Protein extraction, immunoprecipitation (IP) and western blotting. Granulosa cells with or without treatment were washed with ice-cold PBS and harvested in $80 \mu \mathrm{l}$ RIPA buffer (Santa Cruz Biotechnology, Inc.) that was supplemented with 1\% PMSF (Dingguo Biotechnology Co., Beijing, China), $1 \%$ cocktail (Sigma-Aldrich; Merck KGaA, Darmstadt, Germany), and $20 \mathrm{mM} \mathrm{N}$-ethylmaleimide (NEM; Sigma-Aldrich; Merck KGaA, Darmstadt, Germany) for $20 \mathrm{~min}$. The lysates were centrifuged at $11,600 \mathrm{x} \mathrm{g}$ for $10 \mathrm{~min}$, and the supernatant was collected and stored at $-80^{\circ} \mathrm{C}$.

In order to examine the interaction of the proteins in vivo and in vitro, IP was performed. The granulosa cells were washed with ice-cold PBS and lysed on ice in lysis buffer [50 mM Tris- $\mathrm{HCl}$ (pH 7.4), $150 \mathrm{mM} \mathrm{NaCl}, 1 \mathrm{mM}$ EDTA and $1 \%$ Triton X-100] that was supplemented with $1 \%$ PMSF, $1 \%$ cocktail and $20 \mathrm{mM}$ NEM for $20 \mathrm{~min}$; the protein samples were incubated with $1 \mu \mathrm{g}$ of the respective primary antibodies overnight at $4^{\circ} \mathrm{C}$, a polyclonal rabbit anti-SUMO1 antibody (10329-1-AP) and a polyclonal rabbit anti-SUMO2 antibody (11251-1-AP) (both from Proteintech, as described above), a monoclonal mouse anti-HA antibody (M180-3; Medical and Biological Laboratories, Co., Ltd.), and a polyclonal rabbit anti-Flag antibody (20543-1-AP; Proteintech), and subsequently $40 \mu \mathrm{l}$ protein A+G Agarose (Beyotime Biotechnology Co., Ltd., Shanghai, China) was added for $2 \mathrm{~h}$ at $4^{\circ} \mathrm{C}$. Finally, the samples were boiled with $40 \mu 12$ X SDS loading buffer for $5 \mathrm{~min}$, and used immediately for the western blotting.

The proteins were separated on SDS-PAGE and transferred to polyvinylidene fluoride (PVDF) membranes (Millipore, Bedford, MA, USA), blocked with 5\% skimmed milk diluted with TBST [10 mM Tris (pH 7.5), $150 \mathrm{mM} \mathrm{NaCl}$ and $0.1 \%$ Tween-20], and incubated with the corresponding primary antibodies diluted in blocking buffer overnight at $4^{\circ} \mathrm{C}$. [The antibodies were rabbit anti-Aurora B immunoglobulin G ( $\mathrm{IgG}$ ) (1:1,000 dilution; 3094; Cell Signaling Technology, Inc., Danvers, MA, USA), mouse anti- $\beta$-actin IgG (1:1,000 dilution; sc-517582; Santa Cruz Biotechnology, Inc.), mouse anti-HA IgG (1:1,000 dilution; M180-3; Medical and Biological Laboratories, Co., Ltd.), rabbit anti-Flag IgG (1:500 dilution; 20543-1-AP; Proteintech), rabbit anti-phospho-p38 mitogen-activated protein kinase (MAPK) (Thr-180) IgG (1:1,000 dilution; AF4001; Affinity Biosciences, 
Cincinnati, OH, USA), rabbit anti-cyclin-dependent kinase 4 (CDK4) IgG (1:1,000 dilution; A0366; ABclonal Biotech Co.,Ltd., Wobrun,MA,USA), mouse anti-proliferating cell nuclear antigen (PCNA) IgG (1:500 dilution; BM0104; Boster Biological Technology, Ltd.), Fas (1:1,000 dilution; A2639; ABclonal Biotech Co., Ltd.), mouse anti-caspase-8 IgG (1:1,000 dilution; 66093 1-Ig; Proteintech), and caspase-3 (1:200 dilution; sc-136219) and B-cell lymphoma 2 (Bcl-2; 1:200 dilution; sc-509) (both from Santa Cruz Biotechnology, Inc.)]. The following day, the proteins were incubated with matching horseradish peroxidase (HRP)-conjugated secondary antibodies (1:3,000 dilution; Santa Cruz Biotechnology, Inc.), diluted in TBST for $1 \mathrm{~h}$, and washed three times in TBST. Chemiluminescent detection was performed by enhanced chemiluminescence (ECL; Amersham Biosciences, Piscataway, NJ, USA). The images were captured with a Gel-Pro analyzer 4.0 (Media Cybernetics, Silver Spring, MD, USA). The scanning intensities of the western blots was analyzed using ImageJ software to quantify the target bands in comparison with the corresponding $\beta$-actin bands.

Preparation of ovarian follicles. Different follicular development stages, the different granulosa cell layers and diameters were measured. Primary follicles obtained from ovaries of 7-day-old female mice were gently separated using the needle of a $1 \mathrm{ml}$ syringe under a stereo microscope (CKX41SF; Olympus Optical Technology Philippines Inc., Lapu-Lapu City, Philippines), and observed again under an inverted microscope (TE2000-U; Nikon) to collect the follicles with single layer granulosa cells and a diameter $<90 \mu \mathrm{m}$. Secondary follicles obtained from the ovaries of 14-day-old female mice were measured using same procedure as described above, and follicles between 90 and $120 \mu \mathrm{m}$ in diameter with two or three layers of granulosa cells were collected. Antral follicles were obtained from ovaries of 21-day-old female mice following injection with 10 IU PMSG for $48 \mathrm{~h}$, separating out the follicles with a cavity measuring $400-500 \mu \mathrm{m}$ in diameter, and puncturing the cavity to remove follicular fluid. Preovlatory follicles were obtained from the ovaries of 21-day-old female mice following injection with 10 IU PMSG for $48 \mathrm{~h}$, and then $10 \mathrm{IU}$ hCG $7 \mathrm{~h}$ orderly, separating out the follicles with an obvious cavity and measuring $>500 \mu \mathrm{m}$ in diameter, and then similarly puncturing the cavity to remove the follicular fluid. Finally, the four-stage follicles were washed in PBS three times, and centrifuged at $112 \mathrm{xg}$ for $5 \mathrm{~min}$ at room temperature prior to immediate extraction of the proteins.

Quantitative real-time PCR (RT-qPCR) analysis. Total RNA was extracted and reverse-transcribed using a Total RNA extraction kit and RevertAid Strand cDNA Synthesis kit, according to the manufacturer's protocol. Relative mRNA levels of cdk4,PCNA, caspase-3 and bcl-2 were quantified using special primer pairs (Table II) and QuantiFast ${ }^{\circledR}$ SYBR $^{\circledR}$-Green PCR kit (Qiagen, Hilden, Germany). All samples were performed in triplicate to calculate the statistical significance. The gene expression results were normalized to the basal level of $\beta$-actin. The $\mathrm{Ct}\left(2^{-\Delta \Delta \mathrm{Cq}}\right)$ method (26) was used to analyze the relative gene expression data.

Cell cycle, proliferation and apoptosis assay. Granulosa cells were collected for cell cycle assay using the Cell Cycle Detection kit (KeyGen Biotech Co., Ltd., Nanjing,
Table II. Sequences of primer pairs for RT-qPCR.

\begin{tabular}{lll}
\hline Genes & & Primer sequences \\
\hline PCNA & Forward & CAACTTGGAATCCCAGAAC \\
& Reverse & AGACAGTGGAGTGGCTTTT \\
$c d k 4$ & Forward & TCACGCCTGTGGTGGTTAC \\
& Reverse & GGTCGGCTTCTGAGTTTCC \\
bcl-2 & Forward & GCTACCGTCGTGACTTCGC \\
& Reverse & ACCCAGCCTCCGTTATCC \\
caspase-3 & Forward & GGCGTGAAGACATTTTGGAA \\
& Reverse & CGGGAGTAGTCGCCTCTGAA \\
$\beta$-actin & Forward & CCCATCTACGAGGGCTAT \\
& Reverse & TGTCACGCACGATTTCC
\end{tabular}

PCNA, proliferating cell nuclear antigen; cdk4, cyclin-dependent kinase 4.

China) according to the manufacturer's protocol. Cells were fixed with $70 \%$ ethanol overnight at $4^{\circ} \mathrm{C}$, and incubated in $100 \mu \mathrm{l}$ RNase A for $30 \mathrm{~min}$ at $37^{\circ} \mathrm{C}$, and $400 \mu \mathrm{l}$ PI solution was added in the dark for $30 \mathrm{~min}$ at $4^{\circ} \mathrm{C}$. Flow cytometric analysis was conducted using a BD FACSCalibur [excitation wavelength (Ex), $488 \mathrm{~nm}$; emission wavelength (Em), $530 \mathrm{~nm}$; Becton-Dickinson, Mountain View, CA, USA].

Apoptosis was performed using the Annexin V-FITC Apoptosis Detection kit (KeyGen Biotech Co., Ltd.) according to the manufacturer's protocol. Granulosa cells were digested by the pancreatin enzymes without EDTA; each sample was then added to $190 \mu \mathrm{l} 1 \mathrm{X}$ binding buffer and incubated in $5 \mu \mathrm{l}$ Annexin V-FITC for $3 \mathrm{~min}$ in the dark, and then added to $10 \mu \mathrm{l}$ PI solution in the dark for $10 \mathrm{~min}$. Flow cytometric analysis was then performed.

Cell proliferation was assessed using a WST-1 Cell Proliferation Assay kit (Beyotime Institute of Biotechnology) according to the manufacturer's protocol. Briefly, granulosa cells were seeded in 96 -well plates $\left(4 \times 10^{3}\right.$ cells/well), and $10 \mu \mathrm{l}$ freshly prepared WST-1 solution was added to each well, along with the culture medium. The absorbance of the samples was measured after $2 \mathrm{~h}$ using a microplate reader (Bio-Rad Laboratories, Inc., Hercules, CA, USA) at $450 \mathrm{~nm}$.

Statistical analysis. All experiments were performed independently at least three times, and the data are presented as the mean \pm standard deviation. The differences between the groups were analyzed by one-way analysis of variance (ANOVA) followed by LSD test using SPSS statistical software (version 17.0; SPSS, Inc., Chicago, IL, USA). P<0.05 was considered to indicate a statistically significant difference.

\section{Results}

Localization and expression of Aurora B in the mouse follicle. To investigate whether Aurora B affects follicular development and atresia, an IHC study was initially conducted to detect the localization of Aurora B in the mouse follicles at different stages, including primary, secondary, antral and preovulatory 
A

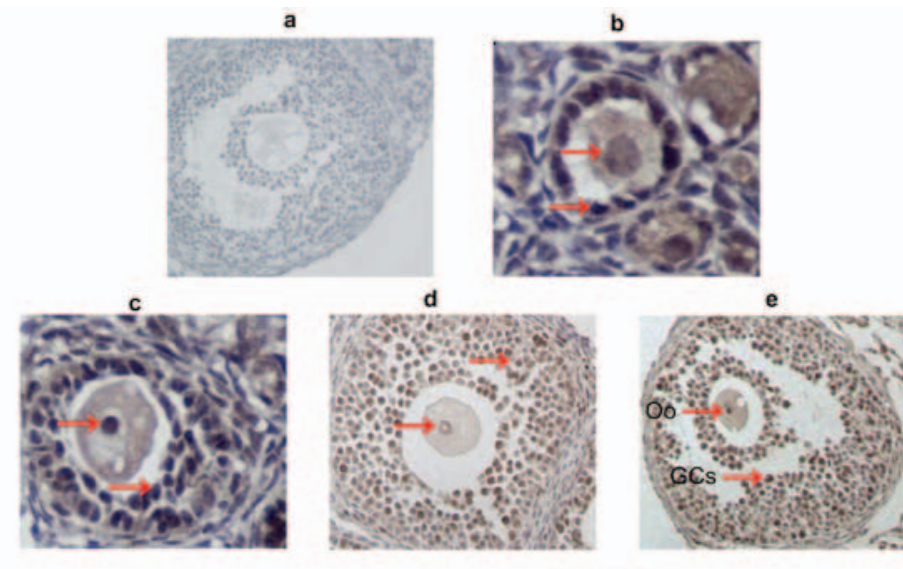

B
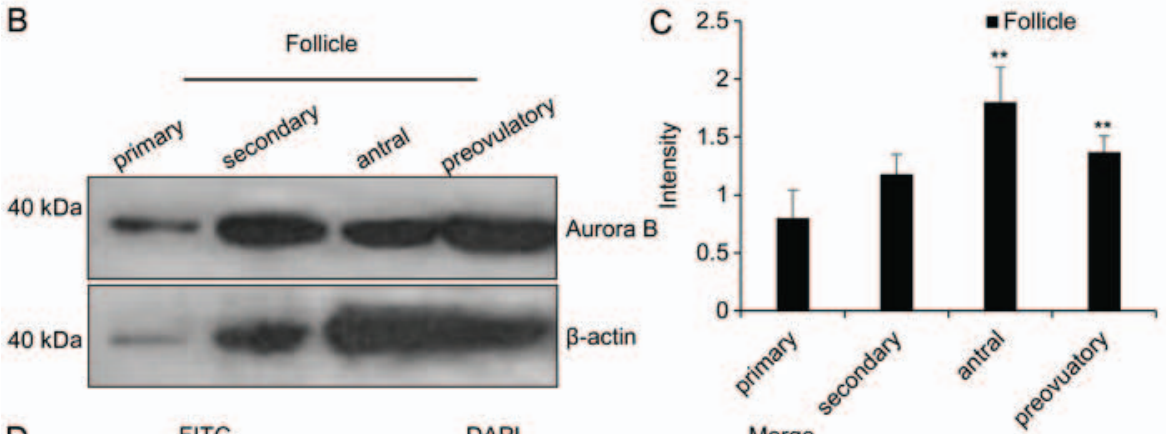

D
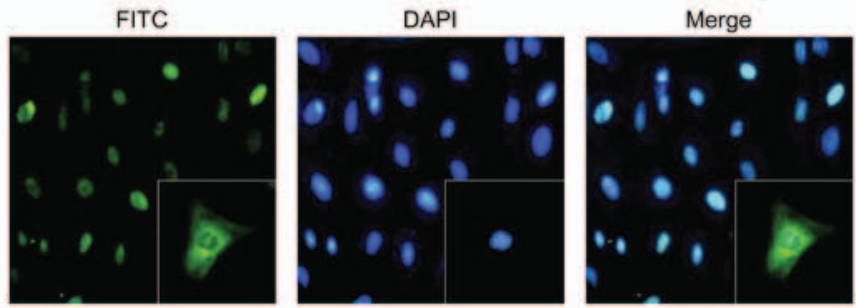

E

GCs
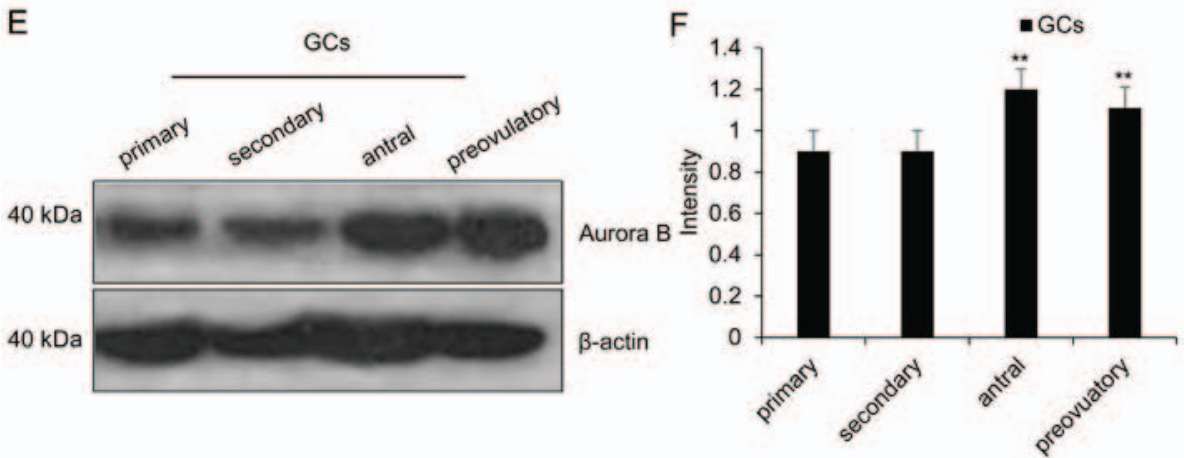

Figure 1. The protein levels, and localization, of Aurora B in the follicles and granulosa cells. (A) Localization of Aurora B in mouse ovarian follicles determined through performing immunohistochemistry of the follicles. (a) Negative control; (b) primary follicle (diameter, $<90 \mu \mathrm{m}$ ); (c) secondary follicle (diameter, $90-120 \mu \mathrm{m}$ ); (d) antral follicle (diameter, 400-500 $\mu \mathrm{m}$ ); and (e) preovulatory follicle (diameter, $>500 \mu \mathrm{m}$ ). The red arrows represent the oocyte and the GCs. (B) Protein level of Aurora B in the follicles at different development stages, as determined using western blotting. (C) Scanning intensity of the western blotting experiments. (D) Localization of Aurora B in the granulosa cells is shown by the green fluorescence (FITC), whereas the nucleus is shown by the blue fluorescence (DAPI). The position of green fluorescence between two granulosa cells shows the midbody during cytokinesis in the lower right-hand corner (images magnified x40). (E) Protein level of Aurora B in the granulosa cells at different follicular development stages as determined using western blotting. (F) The scanning intensity of western blotting. The values are shown using bars. Each experiment was repeated three times, and the values are presented as the mean \pm standard deviation. ${ }^{* *} \mathrm{P}<0.01$. GCs, granulosa cells; FITC, fluorescein isothiocyanate..

follicles (Fig. 1Ab-e). A high concentration of Aurora B was identified in the granulosa cells, whereas a lower concentration appeared in the oocyte (Fig. 1A).

To further explore the protein level of Aurora B in the follicles, western blotting was performed, which determined that Aurora B was expressed in each stage of follicular development (Fig. 1B). The protein level of Aurora B increased with the extent of follicular development, particularly in the antral and preovulatory follicles, where the levels were higher compared with the primary and secondary follicles $(\mathrm{P}<0.01)$ (Fig. 1C). It was surmised that the increased protein level of Aurora B was caused by the proliferation of granulose cells in the follicles. The localization of Aurora B in granulosa cells was determined using ICC. As shown in Fig. 1D, Aurora B was detected in the 
A $0 \mu \mathrm{M}$ $10 \mu \mathrm{M}$ $50 \mu \mathrm{M}$ $100 \mu \mathrm{M}$
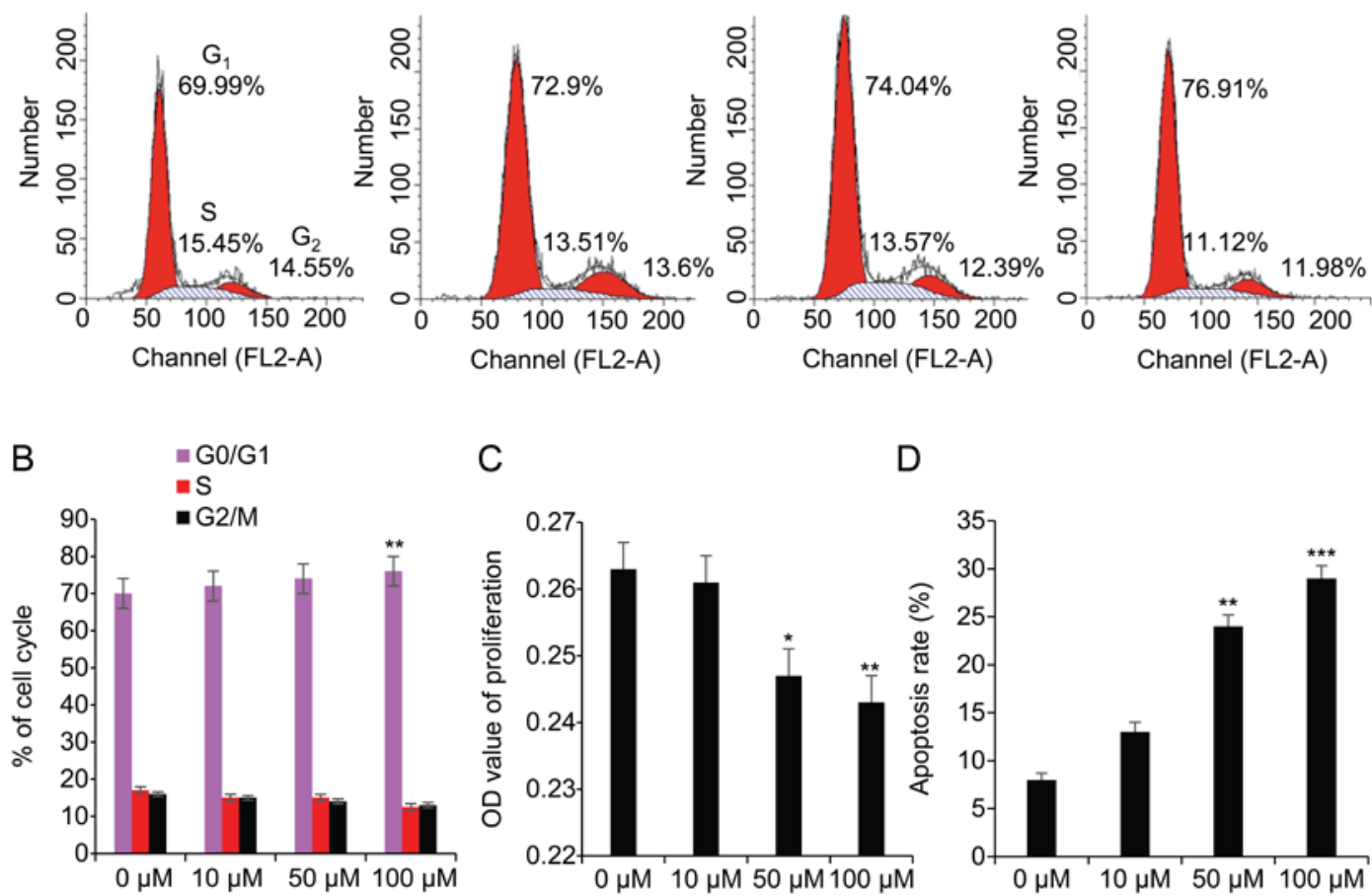

C

D
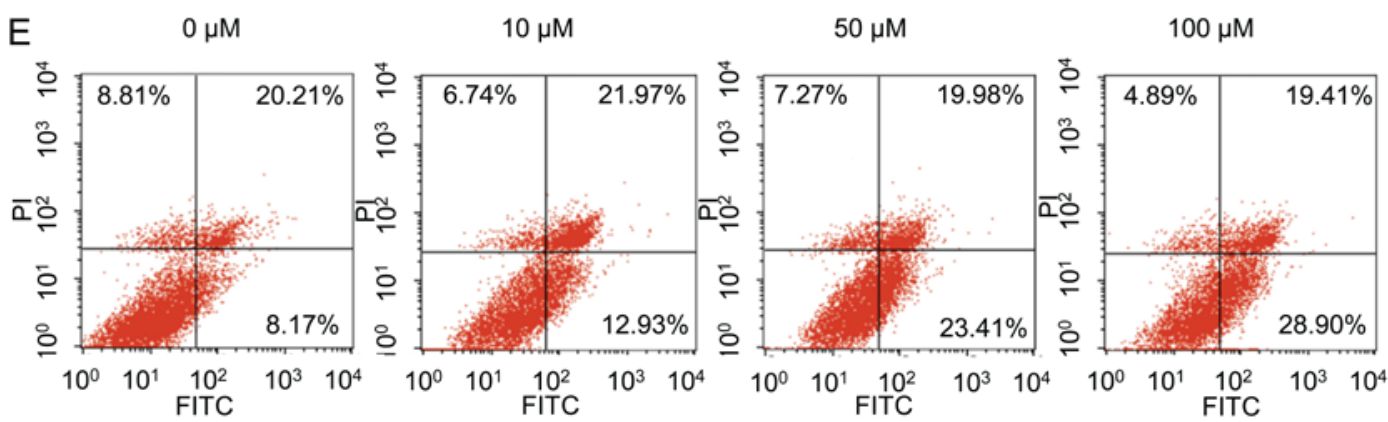

Figure 2. Aurora B impacts the viability of granulosa cells. (A) The cell cycle of granulosa cells was assessed by FACS after the cells were co-cultured with ZM447439 at different concentrations for $48 \mathrm{~h}$. (B) The proportion of each phase of the cell cycle. (C) Proliferation of the granulosa cells was assayed by WST-1. (D) A statistical analysis of the apoptosis rate. Each experiment was repeated three times, and the values are presented as the mean \pm standard deviation; ${ }^{*} \mathrm{P}<0.05,{ }^{* *} \mathrm{P}<0.01$ and ${ }^{* * *} \mathrm{P}<0.001 \mathrm{cf}$. the $0 \mu \mathrm{M}$ data. (E) The apoptosis rate of the granulosa cells was assessed by FACS; the lower-right quadrant represents the early phase apoptosis rate. FACS, fluorescence activated cell sorting; FITC, fluorescein isothiocyanate.

nucleus and, notably, on the midbody and in the cytoplasm around the nucleus during cytokinesis. In addition, the protein level of Aurora B in the granulosa cells was also determined using western blotting. The results demonstrated that Aurora B was expressed in all the stages (Fig. 1E). As expected, protein levels of Aurora B in the antral and preovulatory granulosa cells were significantly higher than in the primary and secondary granulosa cells $(\mathrm{P}<0.01)$ (Fig. 1F).

These results suggested that Aurora B was localized in all stages, and that the protein level increased with follicular development and expansion of the granulosa cells, particularly at the antral stage, where it attained the maximum level. Thus, it was inferred that Aurora B affected the development of the follicles by directly modulating the proliferation and apoptosis of the granulosa cells. However, the role of Aurora B in granulosa cells remains unclear, and continues to be a topic of intense research investigation.

Aurora B impacts the viability of granulosa cells. To determine the role of Aurora B in follicular development, granulosa cells were co-cultured with ZM447439, which inhibits the phosphorylation of Aurora B (data not shown). Serial concentrations (0, 10, 50, and $100 \mu \mathrm{M}$ ) were used, and following a period of $48 \mathrm{~h}$, the ratio of the cell cycle, levels of proliferation, and apoptosis rates were assessed.

As shown in Fig. 2A, the ratio of the cell cycle increased from 69.99 to $76.91 \%$ in the $G_{0} / G_{1}$ phase, decreased from 15.45 to $11.12 \%$ in the $\mathrm{S}$ phase, and decreased from 14.55 to $11.98 \%$ in the $G_{2} / M$ phase. These data suggested that, following treatment with $100 \mu \mathrm{M} Z \mathrm{ZM}$, the ratio was significantly increased $(P<0.01)$ in the $G_{0} / G_{1}$ phase, significantly decreased $(\mathrm{P}<0.05)$ in the $\mathrm{S}$ phase (Fig. $2 \mathrm{~B})$, and cell cycle was arrested at the $G_{1} / S$ phase. A proliferation assay using WST-1 absorbance at $490 \mathrm{~nm}$ revealed that the levels of proliferation were moderately reduced in a dose-dependent manner, which was particularly notable at $50 \mu \mathrm{M}(\mathrm{P}<0.05)$ and $100 \mu \mathrm{M}(\mathrm{P}<0.01)$ compared with $0 \mu \mathrm{M} \mathrm{ZM}$ (Fig. 2C). The apoptotic rate was $8.17,12.93,23.41$ and $28.90 \%$ at 0 , 10, 50, and $100 \mu \mathrm{M} \mathrm{ZM}$, respectively (Fig. 2E), and rapidly increased at $50 \mu \mathrm{M}(\mathrm{P}<0.01)$ and $100 \mu \mathrm{M}(\mathrm{P}<0.001)$ (Fig. 2D). 

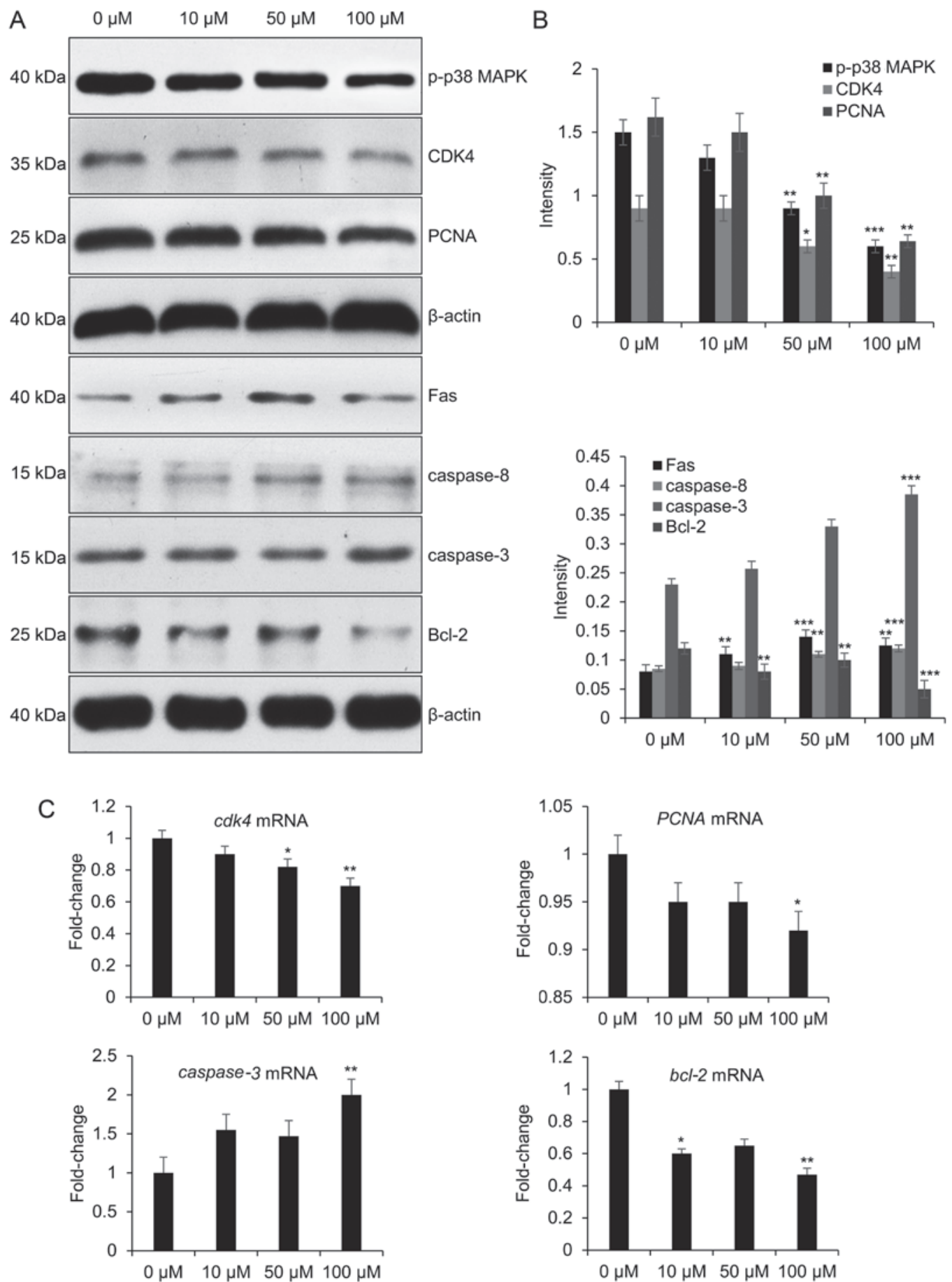

Figure 3. Aurora B impacts the viability related proteins and genes. (A) The protein levels of p-p38 MAPK, CDK4, PCNA, Fas, caspase-8, caspase-3, Bcl-2 were performed by western blotting. (B) Scanning intensities of western blotting are shown. (C) The mRNA levels of cdk4, PCNA, caspase-3 and bcl-2 were determined using RT-qPCR. Each experiment was repeated three times, and the values are presented as the mean \pm standard devidation; ${ }^{*} \mathrm{P}<0.05,{ }^{* * *} \mathrm{P}<0.01$ and ${ }^{* * *} \mathrm{P}<0.001$ cf. the $0 \mu \mathrm{M}$ values. p-p38 MAPK, p-p38 mitogen-activated protein kinase; CDK4, cyclin-dependent kinase 4; PCNA, proliferating cell nuclear antigen; Bcl-2, B-cell lymphoma 2.

These data indicated that blocking Aurora B exerted an impact on the viability of the granulosa cells. The inhibition of Aurora B led to an arrest of the cell cycle at the $\mathrm{G}_{1} / \mathrm{S}$ phase, reduced the proliferation of the cells, and induced apoptosis.

Aurora B mediates $p 38$ MAPK and the FasL/Fas pathway in the granulosa cells. To better understand the molecular mechanisms of Aurora B, western blotting and RT-qPCR were performed using viability-associated proteins and genes, i.e., p38 MAPK, CDK4 (cell-cycle-associated genes) and PCNA (proliferation-associated gene), Fas (apoptotic membrane surface molecule), caspase- 8 and caspase- 3 (apoptosis genes) and Bcl-2 (anti-apoptosis gene).

The western blotting results demonstrated that the protein levels of phosphorylated p38 MAPK (p-p38 MAPK) $(\mathrm{P}<0.01), \mathrm{CDK} 4(\mathrm{P}<0.05), \mathrm{PCNA}(\mathrm{P}<0.01)$ and $\mathrm{Bcl}-2(\mathrm{P}<0.01)$ were significantly decreased at $50 \mu \mathrm{M} \mathrm{ZM}$ (Fig. 3A and B). However, the protein level of Fas $(\mathrm{P}<0.01)$, caspase- 8 


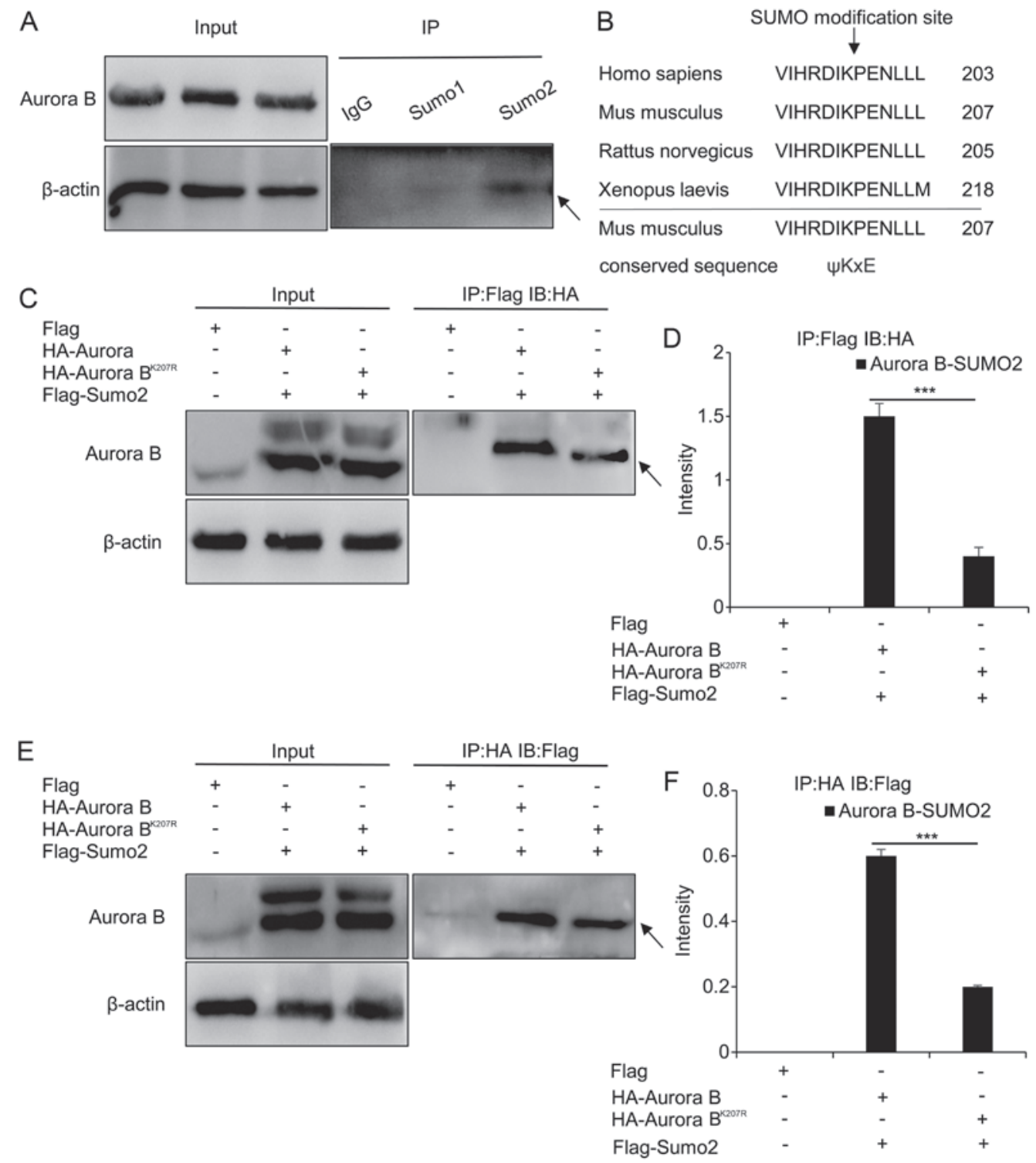

Figure 4. Identification of SUMOylation of Aurora B in vivo and in vitro. (A) Lysates of granulosa cells were immunoprecipitated with IgG, SUMO1 and anti-SUMO2 antibodies, prior to immunoblotting with anti-Aurora B antibody. The arrow represents the complex protein of Aurora B-SUMO2. On the left, the input was immunoblotted with anti-Aurora B antibody and anti- $\beta$-actin antibody, respectively. (B) The SUMOylation site was predicted by SUMOsp2.0 to be at Lys-207 in Mus musculus. (C and D) The co-transfection of HA-Aurora B or HA-Aurora B ${ }^{\mathrm{K} 207 \mathrm{R}}$ with Flag-SUMO2, followed by immunoprecipitation with the anti-Flag antibody and immunoblotting with the anti-HA antibody. The arrow represents the complex protein of Aurora B-SUMO2, and the intensity of the bands was analyzed using ImageJ software. (E and F) Co-transfection of HA-Aurora B or HA-Aurora B ${ }^{\mathrm{K} 207 \mathrm{R}}$ with Flag-SUMO2, followed by immunoprecipitation with the anti-HA antibody and immunoblotting with the anti-Flag antibody. The arrow represents the complex protein of Aurora B-SUMO2, and the intensity of the bands was analyzed using ImageJ software. Each experiment was repeated three times, and the values are presented as the mean \pm standard deviation. ${ }^{* * *} \mathrm{P}<0.001$. SUMO1, anti-small ubiquitin-related modifier 1; IP, immunoprecipitate; IB, immunoblot.

$(\mathrm{P}<0.001)$ and caspase-3 $(\mathrm{P}<0.001)$ were moderately increased at $100 \mu \mathrm{M}$ ZM (Fig. 3A and B). Similarly, the RT-qPCR results revealed that, at $100 \mu \mathrm{M} \mathrm{ZM}$, the mRNA levels of cdk4 $(\mathrm{P}<0.01)$, PCNA $(\mathrm{P}<0.05)$ and bcl-2 $(\mathrm{P}<0.01)$ were reduced, whereas caspase-3 $(\mathrm{P}<0.01)$ was induced (Fig. 3C).

The present study further demonstrated that inactivated Aurora B exerted an effect on the p38 MAPK and FasL/Fas pathways, causing the downregulation of p-p38 MAPK, CDK4, PCNA and Bcl-2 and the upregulation of caspases-8 and -3, which led to an arrest of the cell cycle at $\mathrm{G}_{1} / \mathrm{S}$ phase, decreased cell proliferation and increased apoptosis of the granulosa cells.

Identification of SUMOylation of Aurora B in vivo and in vitro. To investigate whether Aurora B is modified by SUMOs in vivo, the lysates of granulosa cells were immunoprecipitated with $\mathrm{IgG}$, anti-SUMO1 and anti-SUMO2 antibodies, and immunoblotted with Aurora B antibody (Fig. 4A). It was revealed that the band of the Aurora B-SUMO2 complex (52 kDa) was more intense compared with that of the Aurora B-SUMO1 complex, which was almost not discernible; this suggested that Aurora B could be modified by SUMO2 in vivo.

The SUMOylation site of Aurora B was also investigated in vitro. Using SUMOsp2.0 software, data from studies on Homo sapiens and Xenopus laevis were used to predict that the SUMOylation site of Aurora B was located in Lys-207 in Mus musculus (Fig. 4B). Wild HA-Aurora B or mutant HA-Aurora $B^{\text {K207R }}$ was co-transfected with Flag-SUMO2 plasmids, and subsequently the cell lysates were immunoprecipitated 

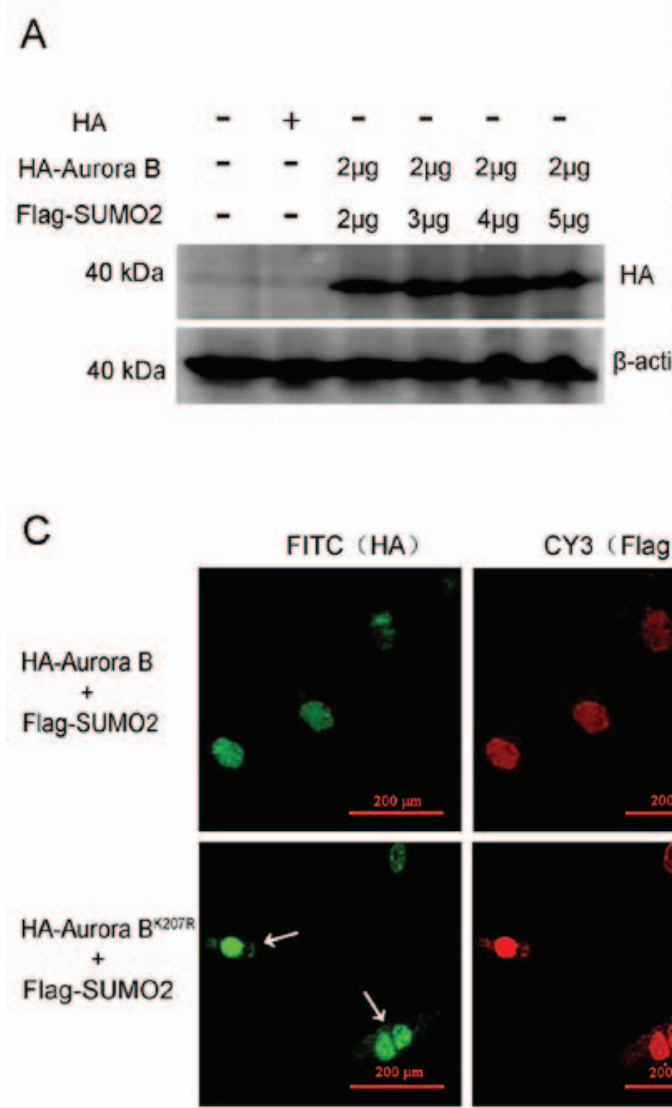

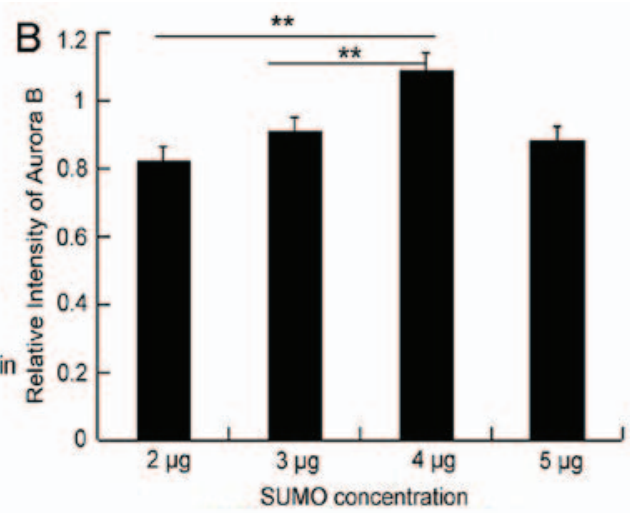

CY3 (Flag)
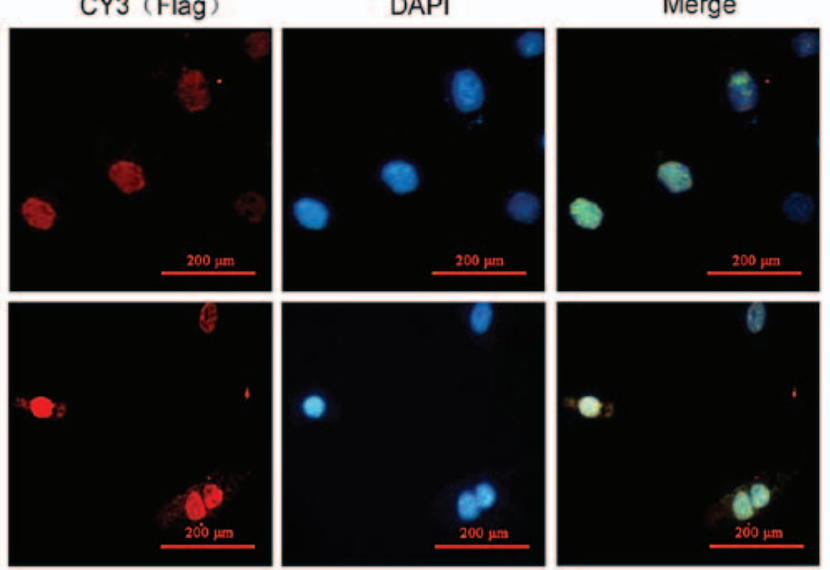

Figure 5. SUMOylation exerts an impact on the protein level and localization of Aurora B in granulosa cells. (A) Granulosa cells were co-transfected with HA-Aurora B $(2 \mu \mathrm{g})$ and Flag-SUMO2 $(2,3,4$, and $5 \mu \mathrm{g})$, and the protein level of Aurora B was determined by western blotting. (B) Scanning intensity analysis of the western blots. Each experiment was repeated three times, and the values are presented as the mean \pm standard deviation. ${ }^{* *} \mathrm{P}<0.01 \mathrm{cf}$. the $2 \mu \mathrm{M}$ value. (C) The co-transfection of HA-Aurora B or HA-Aurora B ${ }^{\mathrm{K} 207 \mathrm{R}}$ with Flag-SUMO2. Localization was observed using immunocytochemistry. FITC indicated the localization of HA-Aurora B and/or HA-Aurora B ${ }^{\text {207R }}$, CY3 indicated the localization of Flag-SUMO2, and DAPI indicated the granulosa cells' nuclei (the images are magnified at x20). SUMO2, small ubiquitin-related modifier 2; FITC, fluorescein isothiocyanate.

with the anti-Flag antibody, and immunoblotted with anti-HA antibody. Notably, the complex protein of Aurora B-SUMO2 was evident, whereas, although the mutant complex protein was also visible (Fig. 4C), the band was less dense compared with the wild-type $(\mathrm{P}<0.001)$ (Fig. 4D). To verify these results, the cell lysates were immunoprecipitated with the anti-HA antibody and immunoblotted with the anti-Flag antibody a second time, which produced similar results $(\mathrm{P}<0.001)$ (Fig. 4E and $\mathrm{F})$.

IP analysis confirmed that Aurora B and SUMO2 interacted in vivo and in vitro, and that Lys-207 was the site of SUMOylation, although it may not be a unique one.

Impact of SUMOylation on the protein stability and localization of Aurora B. The protein stability and localization of Aurora B in the granulosa cells were examined to identify whether SUMOylation could modulate the function of Aurora B. Granulosa cells were co-transfected with Aurora B $(2 \mu \mathrm{g})$ and increasing concentrations of SUMO2 $(2,3,4$ and $5 \mu \mathrm{g})$ for $48 \mathrm{~h}$. Western blotting revealed that the protein level of Aurora B was increased upon increasing the concentration of SUMO2 (Fig. 5A), which reached the highest level of significance with $4 \mu \mathrm{g}$ SUMO2 $(\mathrm{P}<0.01)$ (Fig. 5B). Furthermore, it was revealed that Aurora B was localized in the nuclei of granulosa cells (Fig. 5C, top). However, certain signals of Aurora $\mathrm{B}^{\mathrm{K} 207 \mathrm{R}}$ were also observed in the cytoplasm and in the nuclei, but not in the midbody, during cytokinesis (Fig. 5C, bottom).

These results demonstrated that SUMOylation was able to stabilize the protein level of Aurora B, and that, in terms of localization, Aurora B accumulated in the nuclei of granulosa cells.

SUMOylation of Aurora B exerts an impact on the viability of granulosa cells. It is known that SUMOylation is able to affect the protein stability and localization of Aurora B. However, this raises the question about whether the SUMOylation of mutant Aurora B would have a significant impact on viability of granulosa cells. To investigate this, granulosa cells were transfected with HA, HA-Aurora B, or HA-Aurora B ${ }^{\mathrm{K} 207 \mathrm{R}}$ for $48 \mathrm{~h}$, and subsequently assayed using FACS and WST-1. As shown in Fig. 6A, the ratio of the cell cycle increased from 66.69 to $75.70 \%$ in the $G_{0} / G_{1}$ phase, decreased from 12.93 to $8.54 \%$ in the $\mathrm{S}$ phase, and decreased from 20.39 to $15.76 \%$ in the $\mathrm{G}_{2} / \mathrm{M}$ phase. These data indicated that the ratio was significantly increased $(P<0.01)$ in the $G_{0} / G_{1}$ phase, and was decreased $(P<0.05)$ in the $S$ and $G_{2} / M$ phases by the overexpression of HA-Aurora $\mathrm{B}^{\mathrm{K} 207 \mathrm{R}}$ (Fig. 6B). As expected, the proliferation of granulosa cells was accelerated by the overexpression of HA-Aurora B compared with HA $(\mathrm{P}<0.01)$, although it was significantly suppressed by the overexpression of HA-Aurora $\mathrm{B}^{\mathrm{K} 207 \mathrm{R}}(\mathrm{P}<0.001)$ (Fig. 6C). Similarly, apoptosis 

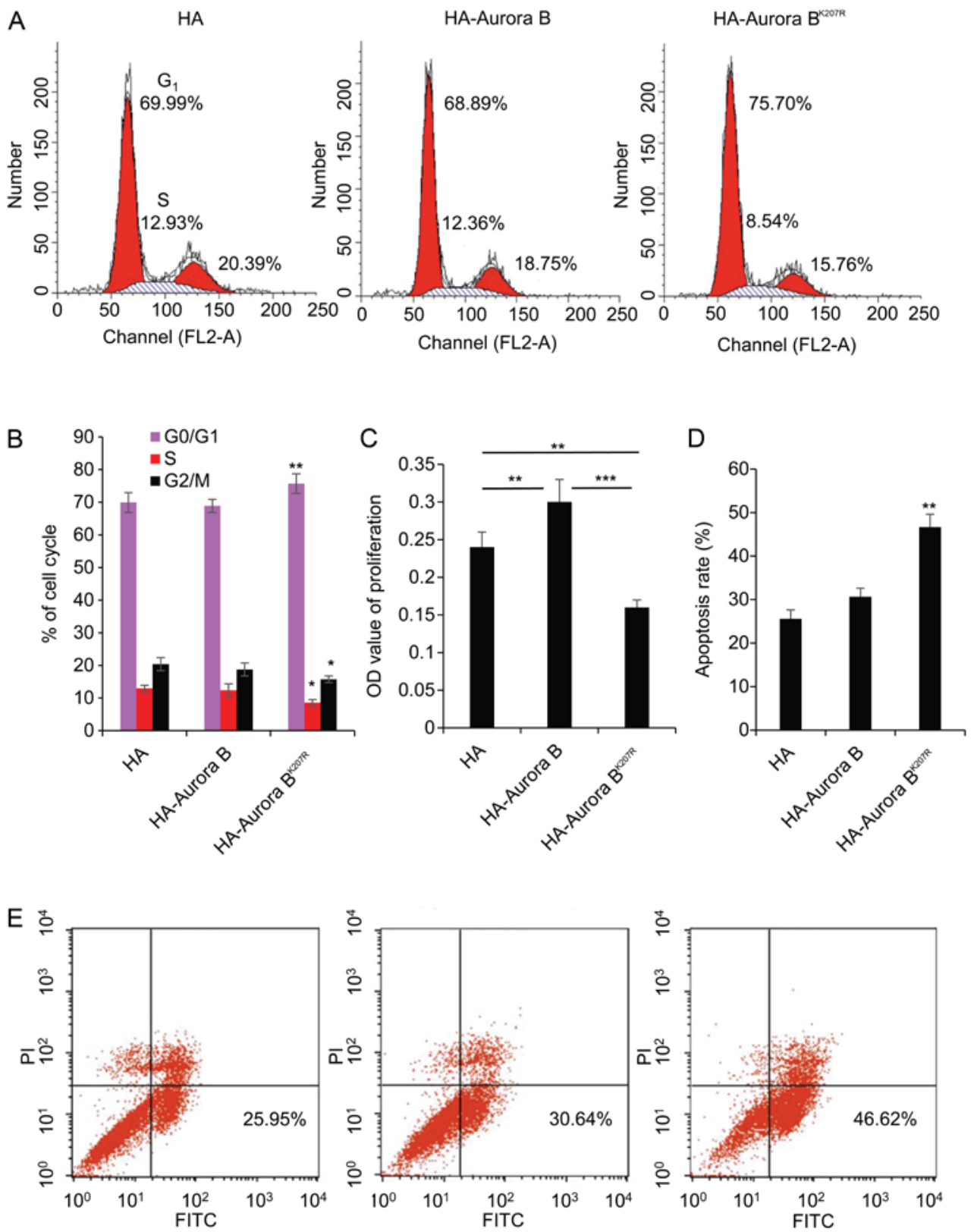

Figure 6. SUMOylation exerts an impacts on cell cycle, apoptosis and proliferation of the granulosa cells. (A) The cell cycle was assessed using FACS after transfection with HA (as control), HA-Aurora B or HA-Aurora $\mathrm{B}^{\mathrm{K} 207 \mathrm{R}}$ for $48 \mathrm{~h}$. (B) The proportion of each phase of the cell cycle. (C) The proliferation of granulosa cells was assayed using WST-1 after transfection of HA (as control), HA-Aurora B, or HA-Aurora B ${ }^{\mathrm{K} 207 \mathrm{R}}$ for 48 h. (D) Statistical analysis of the apoptosis rate. Each experiment was repeated three times, and the values are presented as the mean \pm standard deviation; ${ }^{*} \mathrm{P}<0.05,{ }^{* *} \mathrm{P}<0.01$ and ${ }^{* * *} \mathrm{P}<0.001 \mathrm{cf}$. the $\mathrm{HA}$ values. (E) The apoptotic rate of the granulosa cells was assessed using FACS after transfection of HA (as control), HA-Aurora B or HA-Aurora BK207R for $48 \mathrm{~h}$; the lower-right quadrant represented the early-phase apoptotic rate. FACS, fluorescence-activated cell sorting.

rates were significantly increased from 25.95 to $46.62 \%$ by the overexpression of HA-Aurora $\mathrm{B}^{\mathrm{K} 207 \mathrm{R}}(\mathrm{P}<0.01)$ (Fig. 6D and $\left.\mathrm{E}\right)$.

These results strongly confirm that the SUMOylation of mutant Aurora B affected the viability of granulosa cells by arresting the cell cycle in the $G_{1} / S$ phase, inhibiting proliferation, and inducing apoptosis. The results further proved that the SUMOylation of Aurora B exerts a significant role in follicular development through the granulosa cells.

\section{Discussion}

In the present study, following follicular development, the protein level of Aurora B was revealed to increase significantly until a maximum level was reached in the antral follicle; a similar pattern of protein levels were observed in the granulosa cells. It was inferred that Aurora B in the granulosa cells may contribute to the development of follicles. The present study also showed that follicular growth occurred slowly; the atresia rate increased when follicles were supplemented with an Aurora B inhibitor (data not shown), and the early follicular atresia was mainly caused by the apoptosis of granulosa cells in the follicular wall rather than of cumulus cells, oocytes or the inner and outer theca cells (2). These results further confirmed that Aurora B may modulate follicular growth and atresia by mediating the proliferation and apoptosis of granulosa cells. 
Previous studies have shown that Aurora B exerts a critical role in chromosome-microtubule interactions (27), as it localizes in the kinetochore from prophase to metaphase, and relocalizes in the central spindle and midbody during cytokinesis (28). These studies agree with our results, which revealed that Aurora B was localized in the nucleus and trans-localized on the midbody during cytokinesis. During the shift from the $\mathrm{G}_{1}$ phase to the $S$ phase, the cells must obtain all the necessary materials to maintain a normal growth level using the appropriate regulatory mechanism, particularly at the restriction point, which includes members of the tumor suppressor Rb gene family (pRb, p107 and p130), to prevent excessive proliferation (29). Furthermore, the CDK4/6 and cyclin D kinase activity of the complex serves to release the transcription factor E2F, which is associated with the $\mathrm{S}$ phase and maintains the cell at the checkpoint as it shifts from the $G_{1}$ phase to the $S$ phase through the phosphorylation of $\mathrm{Rb}$ (29). Recent studies have shown that the inhibition of CDK4/6 reduced the growth of neuroblastoma tumors in murine xenograft models $(30,31)$. The p38 MAPK pathway is an important signal transduction pathway, involved in the regulation of cell inflammation, stress response, survival, differentiation, and apoptosis (32). In the present study, the phosphorylation level of p38 MAPK clearly decreased, whereas the mRNA and protein levels of CDK4 and PCNA significantly decreased, which caused the cell cycle to arrest at the $G_{1} / S$ phase. Inactivated Aurora B in the granulosa cells also reduced proliferation and induced apoptosis. These results confirmed that Aurora B exerts an impact on the viability of granulosa cells via the mediation of the p38 MAPK signal pathway.

However, CDK4/6 is able to stop cell division, and may even kill cancer cells by other hub proteins, including p53, a stress-inducible transcription factor that induces cell cycle arrest and apoptosis following DNA damage or cellular stress (33-37). Studies have implied that CDK4 may also be indirectly involved in the regulation of cell apoptosis (34); it could also induce the apoptosis of granulosa cells. On the other hand, the FasL/Fas system induces apoptotic signaling in both normal and tumor cells, whereas in normal mice, the injection of an agonistic anti-Fas antibody induces the number of atretic follicles (38). In vitro studies revealed that Fas mediated apoptosis in cultured granulosa cells, luteal cells and ovarian surface epithelial cells (39-41).

To explore the impact of SUMOylation of Aurora B in follicular development and atresia in mice, the present study, revealed Aurora B conjugation of SUMO2, rather than SUMO1, in vivo and in vitro, Lys-207 was discovered to be a major SUMO2 modification site in the primary granulosa cells, although it may not be a unique one. Recently, studies have indicated that a considerable proportion of SUMOylated proteins do not contain the consensus sites (21-23) and that not all the consensus sequences are SUMOylated, as this process often occurs outside of the consensus sequence (24); furthermore, using software SUMOsp2.0, Lys-292/296 sites of Aurora B were predicted with a high probability. This posed a limitation in our study, and further studies to verify the results identified in the primary granulosa cells are required in the future. It was noted that SUMO2 modification modulated the function of Aurora B, including maintenance of a higher protein level of Aurora B following an increase in SUMO2, and an increase in the localization of Aurora B in the nuclei of the granulosa cells.
The impact of SUMOylation of Aurora B was examined on the granulosa cells, and the results revealed that null SUMOylation of Aurora B (Aurora $\mathrm{B}^{\mathrm{K} 207 \mathrm{R}}$ ) arrested the cell cycle at the $\mathrm{G}_{1} / \mathrm{S}$ phase, suppressed proliferation, and promoted apoptosis. Notably, these results are consistent with the results observed with the inhibition of Aurora B. It was possible to deduce that D205, as a dead kinase domain of Aurora B, would be inactivated by mutant K207R, which triggers structural reorganization. Recently, a study revealed that the overexpression of the SUMO-null form induced polyploidy to the same extent as the Aurora B ${ }^{\mathrm{D} 205 \mathrm{~A}}$ mutant, and that it severely reduced the number of colonies of U2OS cells (20); the two mutants, K207A and D205A, of Aurora B promoted the level of ubiquitination (29). In addition, the facilitation of Aurora B autophosphorylation was decreased by the inhibition of SUMO2 conjugation by transfection with SENP2, which specifically deconjugated SUMO from the target (6). From that study, it was clear that Aurora $\mathrm{B}^{\mathrm{K} 207 \mathrm{~A}}$ decreased autophosphorylation, and increased ubiquitination caused by the structural reorganization that was triggered by the inactivation of the D205 kinase dead domain, resulting in an abnormal localization, cell cycle, proliferation and apoptosis.

Taken together, the results of the present study suggested that Aurora B modulates follicular growth and atresia by affecting the cell cycle of granulosa cells, cell proliferation and apoptosis through regulation of the p-p38 MAPK and FasL/Fas pathways, which causes the downregulation of CDK4, PCNA and Bcl-2, and upregulation of Fas, caspase-8 and caspase-3. Aurora B may be modified by SUMO2 rather than SUMO1 in the granulosa cells, and SUMO2 stabilizes the protein level of Aurora B, leading to an increase in its localization in the nucleus. Lys-207, a conserved sequence, is a major SUMOylation site of Aurora B. The cell cycle is arrested at the $\mathrm{G}_{1} / \mathrm{S}$ phase, proliferation is inhibited, and apoptosis is increased through the null SUMOylation of Aurora B.

In conclusion, the present study explored the protein level pattern of Aurora B in follicular development, the impact of Aurora B and its SUMOylation on follicular development and atresia as mediated by granulosa cells, and the variety of pathways that are involved in its regulation. Our study may provide the theoretical basis for control measures for follicular development and atresia, and further therapy for ovarian disease and infertility, in humans in the future.

\section{Acknowledgements}

This work was supported by the National Key Research and Development Program (2017YFD0501701). We are indebted to Dr Zia Ur Rehman and Dr Rahim Dad Brohi for their important help in revising the manuscript.

\section{Competing interests}

The authors declare that they have no competing interests.

\section{References}

1. Liu XM, Yang FF, Yuan YF, Zhai R and Huo LJ: SUMOylation of mouse $\mathrm{p} 53 \mathrm{~b}$ by SUMO-1 promotes its pro-apoptotic function in ovarian granulosa cells. PLoS One 8: e63680, 2013.

2. Inoue N, Matsuda F, Goto Y and Manabe N: Role of cell-death ligand-receptor system of granulosa cells in selective follicular atresia in porcine ovary. J Reprod Dev 57: 169-175, 2011. 
3. Porcelli L, Guida G, Quatrale AE, Cocco T, Sidella L, Maida I, Iacobazzi RM, Ferretta A, Stolfa DA, Strippoli S, et al: Aurora kinase $\mathrm{B}$ inhibition reduces the proliferation of metastatic melanoma cells and enhances the response to chemotherapy. J Transl Med 13: 26, 2015.

4. Gohard FH, St-Cyr DJ, Tyers M and Earnshaw WC: Targeting the INCENP IN-box-Aurora B interaction to inhibit CPC activity in vivo. Open Biol 4: 140163, 2014.

5. Giet R and Glover DM: Drosophila Aurora B kinase is required for histone $\mathrm{H} 3$ phosphorylation and condensin recruitment during chromosome condensation and to organize the central spindle during cytokinesis. J Cell Biol 152: 669-682, 2001.

6. Ban R, Nishida T and Urano T: Mitotic kinase Aurora-B is regulated by SUMO-2/3 conjugation/deconjugation during mitosis. Genes Cells 16: 652-669, 2011.

7. Andrews PD, Knatko E, Moore WJ and Swedlow JR: Mitotic mechanics: the auroras come into view. Curr Opin Cell Biol 15: 672-683, 2003

8. Bishop JD and Schumacher JM: Phosphorylation of the carboxyl terminus of inner centromere protein (INCENP) by the Aurora B kinase stimulates Aurora B kinase activity. J Biol Chem 277: 27577-27580, 2002.

9. Honda R, Körner R and Nigg EA: Exploring the functional interactions between Aurora B, INCENP, and survivin in mitosis. Mol Biol Cell 14: 3325-3341, 2003.

10. Hay RT: SUMO: a history of modification. Mol Cell 18: $1-12,2005$

11. Geiss-Friedlander R and Melchior F: Concepts in sumoylation: a decade on. Nat Rev Mol Cell Biol 8: 947-956, 2007.

12. Ulrich HD: The fast-growing business of SUMO chains. Mol Cell 32: 301-305, 2008

13. Klein UR, Haindl M, Nigg EA and Muller S: RanBP2 and SENP3 function in a mitotic SUMO2/3 conjugation-deconjugation cycle on Borealin. Mol Biol Cell 20: 410-418, 2009.

14. Makhnevych T, Sydorskyy Y,Xin X, SrikumarT, Vizeacoumar FJ, Jeram SM, Li Z, Bahr S, Andrews BJ, Boone C, et al: Global map of SUMO function revealed by protein-protein interaction and genetic networks. Mol Cell 33: 124-135, 2009.

15. Kamitani T, Nguyen HP and Yeh ET: Preferential modification of nuclear proteins by a novel ubiquitin-like molecule. J Biol Chem 272: 14001-14004, 1997.

16. Sacher M, Pfander B, Hoege C and Jentsch S: Control of Rad52 recombination activity by double-strand break-induced SUMO modification. Nat Cell Biol 8: 1284-1290, 2006.

17. Desterro JM, Rodriguez MS and Hay RT: SUMO-1 modification of IkappaBalpha inhibits NF-kappaB activation. Mol Cell 2: 233-239, 1998.

18. Hoege C, Pfander B, Moldovan GL, Pyrowolakis G and Jentsch S: RAD6-dependent DNA repair is linked to modification of PCNA by ubiquitin and SUMO. Nature 419: 135-141, 2002.

19. Hay RT: SUMO-specific proteases: a twist in the tail. Trends Cell Biol 17: 370-376, 2007.

20. Fernández-Miranda G, Pérez de Castro I, Carmena M, Aguirre-Portolés C, Ruchaud S, Fant X, Montoya G, Earnshaw WC and Malumbres M: SUMOylation modulates the function of Aurora-B kinase. J Cell Sci 123: 2823-2833, 2010.

21. Blomster HA, Hietakangas V, Wu J, Kouvonen P, Hautaniemi S and Sistonen L: Novel proteomics strategy brings insight into the prevalence of SUMO-2 target sites. Mol Cell Proteomics 8: 1382-1390, 2009

22. Golebiowski F, Matic I, Tatham MH, Cole C, Yin Y, Nakamura A, Cox J, Barton GJ, Mann M and Hay RT: System-wide changes to SUMO modifications in response to heat shock. Sci Signal 2: ra24, 2009.

23. Hsiao HH, Meulmeester E, Frank BT, Melchior F and Urlaub H: 'ChopNSpice', a mass spectrometric approach that allows identification of endogenous small ubiquitin-like modifier-conjugated peptides. Mol Cell Proteomics 8: 2664-2675, 2009.
24. Blomster HA, Imanishi SY, Siimes J, Kastu J, Morrice NA, Eriksson JE and Sistonen L: In vivo identification of sumoylation sites by a signature tag and cysteine-targeted affinity purification. J Biol Chem 285: 19324-19329, 2010.

25. Davies EJ, Dong M, Gutekunst M, Närhi K, van Zoggel HJ, Blom S, Nagaraj A, Metsalu T, Oswald E, Erkens-Schulze S, et al: Capturing complex tumour biology in vitro: histological and molecular characterisation of precision cut slices. Sci Rep 5: 17187, 2015.

26. KJ and Schmittgen TD: Analysis of relative gene expression data using real-time quantitative PCR and the 2- $\Delta \Delta C T$ method. Methods 25: 402-408, 2001

27. Hauf S, Cole RW, LaTerra S, Zimmer C, Schnapp G, Walter R, Heckel A, van Meel J, Rieder CL and Peters JM: The small molecule Hesperadin reveals a role for Aurora B in correcting kinetochore-microtubule attachment and in maintaining the spindle assembly checkpoint. J Cell Biol 161: 281-294, 2003.

28. Carmena M and Earnshaw WC: The cellular geography of aurora kinases. Nat Rev Mol Cell Biol 4: 842-854, 2003.

29. Kouraklis G, Theocharis S, Vamvakas P, Vagianos C, Glinavou A, Giaginis C and Sioka C: Cyclin D1 and Rb protein expression and their correlation with prognosis in patients with colon cancer. World J Surg Oncol 4: 5, 2006.

30. Rader J, Russell MR, Hart LS, Nakazawa MS, Belcastro LT, Martinez D, Li Y, Carpenter EL, Attiyeh EF, Diskin SJ, et al: Dual CDK4/CDK6 inhibition induces cell-cycle arrest and senescence in neuroblastoma. Clin Cancer Res 19: 6173-6182, 2013.

31. Rihani A, Vandesompele J, Speleman F and Van Maerken T: Inhibition of CDK4/6 as a novel therapeutic option for neuroblastoma. Cancer Cell Int 15: 76, 2015.

32. Wang YN, Xiao KQ, Liu JL, Dallner G and Guan ZZ: Effect of long term fluoride exposure on lipid composition in rat liver. Toxicology 146: 161-169, 2000.

33. Bukholm IK and Nesland JM: Protein expression of p53, p21 (WAF1/CIP1), bcl-2, Bax, cyclin D1 and pRb in human colon carcinomas. Virchows Arch 436: 224-228, 2000.

34. Elkady AI, Hussein RA and El-Assouli SM: Mechanism of action of Nigella sativa on human colon cancer cells: the suppression of AP-1 and NF-kappaB transcription factors and the induction of cytoprotective genes. Asian Pac J Cancer Prev 16: 7943-7957, 2015.

35. Kollareddy M, Dimitrova E, Vallabhaneni KC, Chan A, Le T, Chauhan KM, Carrero ZI, Ramakrishnan G, Watabe K, Haupt Y, et al: Regulation of nucleotide metabolism by mutant p53 contributes to its gain-of-function activities. Nat Commun 6: 7389,2015

36. Zhu J, Sammons MA, Donahue G, Dou Z, Vedadi M, Getlik M, Barsyte-Lovejoy D, Al-awar R, Katona BW, Shilatifard A, et al: Gain-of-function p53 mutants co-opt chromatin pathways to drive cancer growth. Nature 525: 206-211, 2015.

37. Tsou SH, Hou MH, Hsu LC, Chen TM and Chen YH: Gain-of-function p53 mutant with 21-bp deletion confers susceptibility to multidrug resistance in MCF-7 cells. Int J Mol Med 37: 233-242, 2016.

38. Quirk SM, Cowan RG, Joshi SG and Henrikson KP: Fas antigen-mediated apoptosis in human granulosa/luteal cells. Biol Reprod 52: 279-287, 1995 .

39. Quirk SM, Cowan RG and Huber SH: Fas antigen-mediated apoptosis of ovarian surface epithelial cells. Endocrinology 138: 4558-4566, 1997

40. Quirk SM, Porter DA, Huber SC and Cowan RG: Potentiation of Fas-mediated apoptosis of murine granulosa cells by interferon-gamma, tumor necrosis factor-alpha, and cycloheximide. Endocrinology 139: 4860-4869, 1998.

41. Vickers SL, Cowan RG, Harman RM, Porter DA and Quirk SM: Expression and activity of the Fas antigen in bovine ovarian follicle cells. Biol Reprod 62: 54-61, 2000.

This work is licensed under a Creative Commons

Attribution-NonCommercial-NoDerivatives 4.0

International (CC BY-NC-ND 4.0) License. 